\title{
Postshock crouching: Familiarity with the shock situation
}

ROBERT J. BLANCHARD, TED E. DIELMAN, AND D. CAROLINE BLANCHARD

UNIVERSITY OF HAWAII

Two groups of rats were given seven brief foot shocks at 1 intervals. The Ss who had been placed in the shock situations $24 h$ before shock crouched less after the second and all succeeding shocks than the group which had only $1 / 2 \mathrm{~h}$ habituation to the shock situation, thus indicating that the cues of the shock situation influence postshock crouching.

Blanchard, Dielman, \& Blanchard (1968) have shown that a single electric foot shock produces increased crouching lasting up to $3 \mathrm{~h}$ after shock. In view of the possible influence of crouching on other dependent variables of experiments involving foot shock, it is of interest to determine if such crouching is solely an unconditioned reaction to shock, or if it is influenced by the cues of the shock situation. The present experiment therefore examined the relationship between familiarity with the shock situation and postshock crouching. In addition, the effects of repeated shocks were observed.

Subjects

The Ss were 16 naive female albino rats, from 135-156 days of age, from the colony maintained by the University of Hawaii Department of Psychology. Apparatus

The eight shock chambers were those used by Blanchard et al (1968). They were located in a sound attenuating room facing a one-way vision mirror, enabling the $E$ to rate eight $\mathrm{Ss}$ simultaneously. Grason-Stadler Model E1064 GS shock sources were used to deliver shock to the grids.

\section{Procedure}

The 16 Ss were randomly divided into two equal groups, a 24-h habituation group and a 1/2-h habituation group. Feeders and water tubes were added to the shock chambers, providing ad lib access to food and water for all Ss. Half of the Group $24 \mathrm{Ss}$ were placed in the experimental chambers $24 \mathrm{~h}$ before the first shock. One-half hour before shock these Ss were removed, stroked for $15 \mathrm{sec}$, and replaced. At the same time, four Ss from Group $1 / 2$ were loaded into the remaining boxes, and rating was begun. The rating procedure and categories were identical to those used by Blanchard et al (1968). After $30 \mathrm{~min}$, all Ss received a $1.0 \mathrm{~mA}$ shock of 1 sec duration, which was repeated at hourly intervals for a total of seven shocks.

Two days later, the experiment was replicated with the remaining rats. The raters were unaware of the Ss' experimental conditions.

\section{Results and Discussion}

Differences between groups on the stand, groom, and active categories were small and unsystematic. The 24-h group had 5.6, 6.1, and $8.3 \%$ of its responses classified as standing, grooming, and activity, in contrast to the $7.3,6.3$, and $8.6 \%$ responses, respectively, of the $1 / 2-\mathrm{h}$ group. The proportion of responses in the crouch and lie categories, as a function of successive shocks, is presented in Fig. 1. During both the preshock period and the $1 \mathrm{~h}$ period following the first shock, Groups 24 and $1 / 2$ did not greatly differ in their tendencies to lie. For the remaining six shocks, lying responses were considerably more frequent for Group 24 than for Group 1/2. The crouching response also showed no significant preshock or first shock differences. On the second and subsequent shocks, however, Group $1 / 2$ continued to crouch strongly, while crouching for Group 24 declined. A test of the overall shock differences in crouching showed that these differences were statistically reliable $(t=4.52, d f=14, p<.001)$.

The finding that postshock crouching is grossly

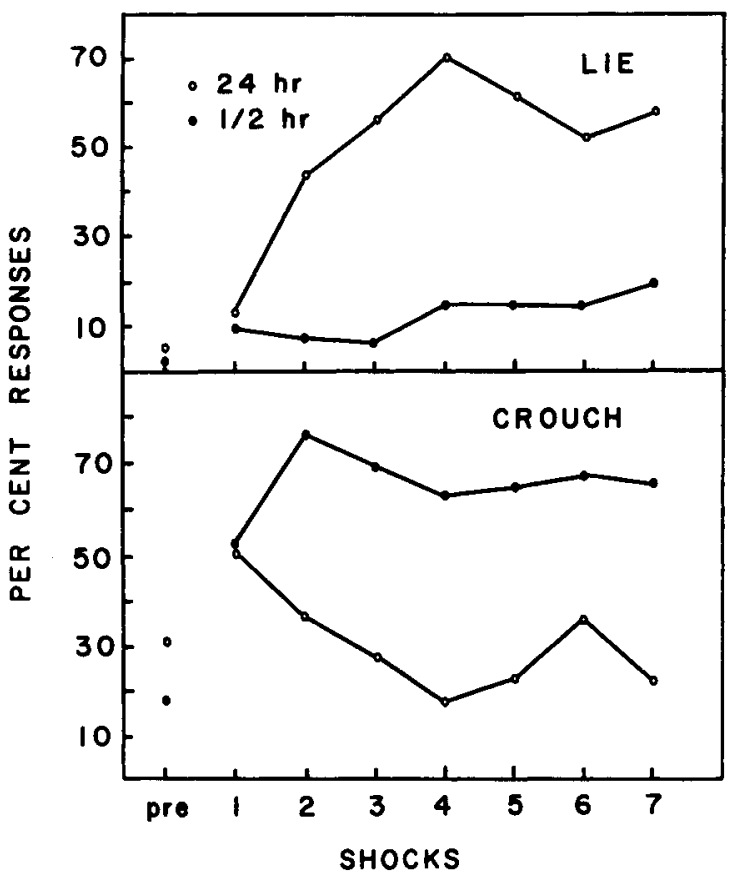

Fig. 1. The proportion of lying and crouching responses during 1-h periods following seven shocks, for groups with 24 or $1 / 2$-h of familiarity with the shock situation. 
attenuated by preshock exposure to the shock situation indicates that crouching may be influenced by stimuli associated with shock as well as by the shock itself. This finding appears to indicate that postshock crouching may reflect a conditioned response. One possible nonlearning interpretation, that crouching is an index of some long lasting unconditioned emotional response to shock, fails to account for several of the findings of the present study. Specifically, if crouching reflects such an unconditioned response, then the emotional reactions accompanying novel stimuli may have summated with the emotionality produced by foot shock, to result in greater crouching for nonhabituated Ss. This interpretation depends heavily on a finding of greater preshock crouching for the nonhabituated group. In fact, although preshock differences did not reach an acceptable level of significance, Group $1 / 2$ crouched less than Group 24. Further, this hypothesis would also predict more crouching for the $1 / 2-\mathrm{h}$ group after the first shock, with parallel crouching functions for the two groups over succeeding shocks. The present finding of no difference after the first shock, with diverging crouching functions over successive shocks, does not support this hypothesis.

With respect to a conditioned response view of crouching, at least two interpretations might be made. The first is that crouching is an acquired reaction of the rat which effectively minimizes the pain of foot shock. The second is Miller's (1951) suggestion that crouching is an index of fear. The present ex- periment does not offer conclusive results with which to reject either of these hypotheses. The present results, in conjunction with Carlton \& Vogel's (1967) finding that prior habituation of a discriminative CS retards the development of a CER to that CS, do suggest that habituation to the apparatus cues of the shock situation may have produced a deficit in the development of conditioned responses in the situation.

Finally, it is of interest to note that a comparison of the crouching proportions of the present study and of Blanchard et al (1968) indicate that the crouching phenomenon is quite stable. In the first hour after shock 1 , both the $1 / 2-$ and $24-h$ groups made about $52 \%$ crouching responses, which may be compared to the $66 \%$ crouching responses during the first postshock hour of the group receiving a slightly more intense shock $(1.3 \mathrm{~mA})$ in the earlier study. Preshock lying, and lying during the first hour after shock 1 were also very similar for the two studies. Thus, in addition to indicating that crouching is influenced by the cues of the shock situation, the present study also serves as a partial replication of Blanchard et al (1968).

\section{References}

BLANCHARD, R. J., DIELMAN, T. E., \& BLANCHARD, D. C. Prolonged aftereffects of a single foot shock. Psychon. Sci., 1968, $10,327-328$.

CARLTON, P. L., \& VOGEL, J. R. Habituation and conditioning. J. comp. physiol. Psychol., 1967, 63, 348-351.

MILLER, N. E. Learnable drives and rewards. In S. S. Stevens (Ed.), Handbook of experimental psychology. New York: Wiley, 1951. 